\title{
SYNCHRONIZING KNOWLEDGE IN MILITARY DECISION MAKING: A RESEARCH APPROACH FOR EXPLORING THE EFFECTS OF ORGANIZATIONAL CULTURE
}

\author{
Larry George, Robert Morris University, lxgst3@rmu.edu \\ Robert Joseph Skovira, Robert Morris University, skovira@rmu.edu \\ A. J. Grant, Robert Morris University, granta@rmu.edu \\ Ann D. Jabro, Robert Morris University, jabro@rmu.edu
}

\begin{abstract}
Decision making in such high stress environments as a military operations center requires synchronization of available knowledge and information systems capabilities. Investigating the effects of organizational culture on the military decision making process can be difficult due to limited access to participants and security classification issues. A qualitative approach for exploratory research in this environment based on an information landscape model and textual analysis methods is presented.
\end{abstract}

Keywords: Organizational Culture, Decision Making, Information Landscape, Information Operations, Ethnography, Semiotics, Rhetoric

\section{INTRODUCTION}

Organizations need timely, accurate information for leaders to make effective decisions. This is especially true for military organizations, where decisions put lives, and not just economic resources, at risk. Operating in an environment of "volatility, uncertainty, chaos, and ambiguity" [44] complicates the ability of commanders and their staffs to synchronize available knowledge and to incorporate innovations into their information systems.

Computer-based decision support systems can help assess available information and model possible outcomes of alternative courses of action for comparison. Such systems, however, must balance a need for timely results with the desire to accurately model the complexity of the environment. Research in this area is complicated by lack of access to participants during combat decision making and in some cases by security considerations. This paper presents a qualitative research approach for initiating exploratory research in this information environment.

\section{Military Decision Making}

Decisions in a military context, like decisions in civilian organizations, range from the mundane (what time to hold the staff meeting) to the critical (should lives be risked to seize a particular hilltop). Here, the phrase military decision making refers to what Klein and Calderwood [34] characterized as "commandand-control decision making.” This category features "high-level integration of near real-time information for the purpose of deciding how best to utilize force application in a 'battle' environment under varying degrees of uncertainty and time pressures" [34]. Decisions are thus how a commander translates a vision of an end state into actions [67]. One could argue that this could be characterized as problem solving or planning rather than "decision making," but, as Klein [33] notes, in natural settings (that is, outside the laboratory) "the distinctions between problem solving and decision making blur."

In traditional military planning, tasks (presumably related to an overall strategic objective) are proposed by staff experts and combined into courses of action. The commander decides what course of action to follow. The selected course of actions is communicated to subordinate organizations and executed to accomplish an assigned mission. The success criteria associated with this approach has historically been assessing the percentage of tasks completed (aircraft sorties flown, missiles launched, buildings destroyed), rather than evaluating whether the desired effect (protecting the local population from enemy attacks) was attained.

In recent years, the U. S. military has begun to focus more on the desired effects when comparing alternative courses of action [68]. Computer-based decision support systems have been developed to model the decision space and help find an optimal course of action through simulation. Given the uncertainty inherent in the battlefield environment, 
some researchers [68, 69] have advocated a probabilistic modeling approach using Bayesian Nets or influence nets to relate available actions to probable outcomes. Designers of such systems rely on subject matter experts (SME) to establish causal relationships among the nodes in the network and to estimate the probability that a given relationship will exist. The system designers must, therefore, have an appreciation of the organizations and their cultures to incorporate the subjective assessments of the SME into a computer information system in a manner which meets the decision maker's requirements.

Developing such an understanding is particularly important when evaluating the possible uses of new capabilities. Here the experience base of the decision makers may be limited and the descriptive language used to bring together the subject experts, the decision maker, and the system designer can be critical [38]. Understanding the system implications of one such new capability, so-called information operations, became the focus of a research effort described in the following section.

\section{Information Operations Research Problem}

Military information has historically taken the form of intelligence about the adversary, knowledge of the environment, or management information on the state of people and materiel resources. In the late $20^{\text {th }}$ century, information moved from a useful, if sometimes uncertain, element of the decision making process to an essential element of combat power. It became essential because better information technology and systems could give one side an asymmetrical advantage - allowing more to be accomplished with fewer assets [11]. The American military, for example, capitalized on their superior sensors, communications, decision support systems, and precision weapons to defeat the Iraqi army thoroughly in a very short time period during the first Gulf War in 1991, leading Campen to call it the "First Information War" [11] - although the "First Information Technology War" might be a more accurate characterization.

Today, information has evolved from an enabler of other combat systems to a capability in its own right, one which can achieve a desired effect on the adversary and which, conversely, must also be protected from disruption or deception. Information has become a desired commodity and hence a potential domain of conflict. The phrase "information warfare" appeared first in the military lexicon [12], but has also become a reality in the broader society. The lexicon has continued to evolve to label concepts and problems affecting both personal and business information. For example, hacking, personal information protection, spam, scams, information viruses, marketing, and competitive intelligence have become familiar problems [16].

Information operations are "primarily concerned with affecting decisions and decision-making processes, while at the same time defending friendly decisionmaking processes" [32]. Information operations (IO) can help shape the behavior of an adversary decision maker by adding, modifying, or removing information from a decision maker's environment, affecting the infrastructure that supports decision making, and influencing how the "people receive, process, interpret, and use data, information, and knowledge" [32]. IO has become a major consideration in planning operations for modern warfare [66]. However, despite the emphasis on information operations by senior military leaders [17, 32], a number of sources indicated concern that information operations were not synchronized into the planning processes in military operations centers [3, 37, 40, 45, 46, 56, 63, 69].

Examining this discrepancy led to an exploratory research project whose objective was to identify organizational and cultural factors in U. S. ground forces (Army and Marine Corps) which could be influencing decisions about using information operations. A key challenge for this research was to develop a methodology which both encompassed the complexity of the information situation and accommodated the limited access to information and users due to geography and security classification. The remainder of this paper describes the methodology and illustrates its use with findings from the research project.

\section{METHODOLOGY DEVELOPMENT}

Following a review of the relevant literature, this section will describe the development of a methodology which overcame the limitations imposed by the security classifications and access to participants in the information operations field and, more importantly, yielded useful insights into the information operations (IO) decision making process. The well-established qualitative approach of textual analysis was selected, using articles in professional military journals as the source data. Sadler [55] and Lawson [36] had identified professional military journals as sites of discourse and suggested analysis using methods from rhetorical criticism. Following Peräkylä's [48] recommendation to use a variety of 
approaches when relying solely on textual materials, the methodology incorporated methods from ethnosemantics, semiotics, and rhetorical criticism.

The initial step, however, was to use an information landscape model $[59,60]$ as a guide for an abductive research approach. The model directs the researcher's attention to the cultural aspects of an information situation and suggests that the situation should be viewed through frames of information use. The model also provided a means for viewing the results from the individual methodologies in an information context and for bringing alternative frames (such as public relations) into play.

\section{Military Decision Making}

Current research in military decision making has tended to focus on either (a) cognitive aspects of decision making by individuals or teams [35] (b) computer models which establish probabilistic relationships between actions taken and effects achieved, then vary these through simulated scenarios to discover algorithms for optimizing the selection of a course of action [37, 69]; or (c) an analytical game theory approach which attempts to develop mathematical models for understanding the decision process $[27,49]$. The computer modeling approach also supports simulations and wargaming which allow operators to try new concepts or organizational constructs gain experience, and discover deficiencies before having to execute them in actual operations [37].

Army doctrine has advocated a particular model as the preferred method for commanders: a structured, analytic approach known as the Military Decision Making Process (MDMP) [67]. The MDMP is an optimization approach which assumes that even in complex situations there will be an optimal course of action and that a decision maker will seek to know and act on it. It is a very staff-driven process and requires "time to deliberately and methodically contrast [a COA] with alternatives using a common set of abstract evaluation dimensions” [53].

Ross et al [53] have proposed an alternative decision making paradigm, called the "Recognition Planning Model" (RPM), which takes a "bounded rationality" [57] view of decision making. It is based on the Recognition Primed Decision approach [35]. Here the commander's "knowledge, training, and experience generally help in correctly assessing a situation and developing and mentally wargaming a plausible COA" which is then provided to the staff to test and (assuming they find no flaws to negate the COA) to “operationalize” [53]. RPM advocates have advanced evidence that this intuitive decision process can outperform analytical processes [53]. As Simon notes, however, "the price...for working with the more realistic but less regular models is that [they] generally find only satisfactory solutions, not optimal” [58].

The two models provide different frames for viewing the IO decision making process. MDMP emphasizes organizational culture and process, and seeks to make knowledge explicit [15], to become what Norman calls "knowledge in the world" [42]. RPM focuses on the commander's cognitive approach in the context of an organizational culture and relies on tacit knowledge [15] or "knowledge in the head" of the commander [42]. This is a knowledge mapping situation where the operations center staff must try to make the tacit knowledge in the organization or in the commander's head explicit [15, 61]

\section{Information Landscape Model}

Military decision making takes place in complex information or knowledge ecologies, with an admixture of process, technology, and people. Skovira $[59,60]$ has described an abductive research approach which specified an information landscape model to guide ethnographic fieldwork. The model has been successfully applied in an investigation of stress management of Slovak IT professionals [60], information governance issues in the virtual meetings of a community of practice [23], and the effects of culture on curricula development [10]. It is a "view of an organization that envisions people, information flows, and business processes as constituting a holistic and dynamic multidimensional system” [59, $10]$.

The model includes frames of information use and cultural dimensions. Frames are a means for helping a participant in an information situation render "what would otherwise be a meaningless aspect of a scene into something that is meaningful" [24]. Bolman and Deal [7] describe a frame as "a set of ideas that enable you to see and understand more clearly what goes on day to day." They advocate viewing an organizational situation through a variety of frames or "reframing" as an approach for "gaining clarity, generating new options, and finding strategies that work" [7].

Political, financial, legal, ethical, or technological frames may be useful in analyzing a given information situation. While technology and technological frames influence the informational 
landscape, the information landscape model focuses on the "personal human aspect of informational situations and information use" [59]. As Rosen [52] observed, military organizations can be regarded "as complex political communities in which the central concerns are those of any political community: who should rule, and how the 'citizens' should live." The political frame was therefore a logical starting point for analysis. The political frame of use is about authority over information flows, and includes modes of information governance: technocratic utopianism, anarchy, feudalism, monarchy, and federalism [14]. Another frame was drawn from public relations research to explore the similarities between some aspects of information operations and public relations [31].

Examining the frames of an information situation exposes the cultural context for the situation and leads the researcher to consider the influence of an organization's culture on the information situation. One way to envision the information landscape model is shown in Figure 1. Here the information situation is a decision about using information operations (IO), made through the military decision making process (MDMP), in the context of the military culture, and as viewed in the political frame.

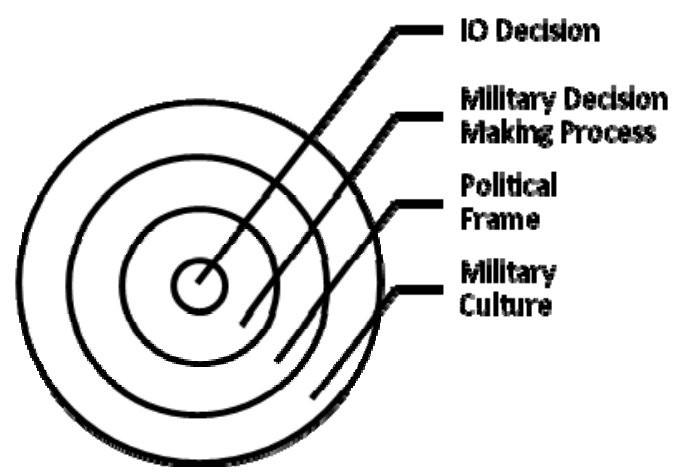

Figure 1. Information Landscape

\section{Qualitative Approach}

The design of research starts with the "perspectives or world views" that the researcher brings to the research [43]. Qualitative research has been associated with the social constructivist or interpretive perspective [13, 47], which "asserts that reality, as well as our knowledge thereof, are social products and hence incapable of being understood independent of the social actors (including the researchers) that construct and make sense of that reality" [43].

Military decision making is a human activity, one which increasingly uses information systems, which, in turn have been characterized as "social interaction systems" [38]. The decisions considered are thus made in what Spradley calls "social situations," characterized by three fundamental elements: "a place, actors, and activities" [62]. Here, the place is a military operations area, the actors are commanders and their staffs, and the activity is deciding on a course of action to meet mission requirements. It is the ability of qualitative procedures to "describe a social setting as it is perceived by those involved in the setting (the archetypal 'users')" that made it appropriate for this type of research problem [30]. Since there was no a priori theory in this area, the research was "emergent rather than tightly preconfigured" [13 and "open...[to] the discovery of novel or unexpected issues that may come to light as a study progresses" [4].

\section{Information Operations Artifacts}

Data was collected by reading accounts of information operations users, typically found in professional military journals or in military research monographs. These cultural artifacts were analyzed for common themes, issues and patterns of behavior, and the culture of the IO practitioners and the decision makers. As Hodder [28] notes, "texts are of importance for qualitative research because, in general terms, access can be easy and low cost, because the information provided differ from and may not be available in spoken form, and because texts endure and thus give historical insight." In addition, "textual communicative practices are a vital way in which organizations constitute 'reality' and the forms of knowledge appropriate to it" [1]. Ridderhof, for example, applied deconstruction techniques to military vision statements and identified key organizational issues and attitudes and for "generating ideas for further study" [51].

Even if IO practitioners were available for observation and interview, the analysis their documents would be inherently useful. Documents created by members of an organization or culture are "instances of social action" and should be treated as "speech acts or events with common cultural conventions and recognizable genres” [2]. Prior [2] maintains that "documentary work may be the main undertaking of qualitative research" and that examining artifacts "provides insights into the most fundamental aspects of human culture" [50]. Ethnosemantics, semiotic analysis, and rhetorical criticism were chosen as "analytic strategies that reflect and respect the intrinsic complexity of social organization, the forms of social action, and the conventions of social representation” [2]. 
Initially, these three methods were viewed as separate approaches, but what emerged from the analysis was a process wherein the results of the ethnosemantic effort provided an entry point for the structural semiotic analysis, which, in turn, supported the rhetorical criticism by identifying key language processes in the narratives. In the context of the information landscape model, each of the methods was a frame or perspective on the underlying cultural and linguistic processes at work. The model also provided the opportunity to view the information situation from alternative perspectives, specifically the political frame and the public relations frame.

\section{Cultural Dimensions}

The information landscape model provides an abductive research approach for investigating "what is going on here?" in an information situation [24]. Abduction is a form of logic comparable to Deduction and Induction. It was advanced by Charles Sanders Peirce (a founder of semiotics) as a means for generating hypothesis to guide analysis [72]. That is, when faced with a surprising phenomenon, a plausible hypothesis which could explain the phenomenon is advanced and checked against observed values $[19,72]$. The information landscape model provided such a starting point for the IO analysis by suggesting the role of cultural factors in information situations.

The cultural context for an information situation has dimensions, including power distance, individualismcollectivism, masculinity-femininity, uncertainty avoidance, and long term and short term orientation [29, 59]. Hofstede and Hofstede originally identified these dimensions in empirical studies which examined national cultural differences in along these axes, but have also applied them in studies of organizational cultures [29]. These cultural dimensions provided a framework for seeking patterns in the data. A brief explanation of each dimension taken from Hofstede and Hofstede [29] follows.

Power distance is "the extent to which the less powerful members of institutions and organizations...expect and accept that power is distributed unequally” [29]. Individualismcollectivism has to do with whether the needs of the group or the needs of the individual prevail. Masculinity-femininity is Hofstede and Hofstede's name for a cultural dimension about "the perspectives driving achievement and nurturance in cultural situations" [60]. Uncertainty avoidance is defined as "the extent to which the members of a culture feel threatened by ambiguous or unknown situations" [29]. The final cultural dimension has to do with how the culture thinks about the past, present, and future. A society with a long term orientation fosters "virtues oriented towards future rewards" while a short term orientation supports "virtues related to the past and present” [29].

\section{Ethnosemantic Approach}

Within a social situation there are "patterns of behavior, artifacts, and knowledge that people have learned or created", which is one definition of culture [62]. Culture is also "the acquired knowledge people use to interpret experience and generate behavior"; "an organization of things, the meaning given by people to objects, places, and activities' [62]; and "stable and enduring systems of meaning shared" [60].

One approach to understanding how things are accomplished in an organization is to examine its culture, using an anthropological approach known as ethnography - an effort to observe a culture and develop a "thick description" [22, 54]. Thick descriptions build an understanding of a specific culture or aspects of a given culture through the observation and recording of the details of that culture's behavior. The ethnographer observes cultural behaviors (what people do), cultural artifacts (things people make and use), and speech messages (what people say) [62]. Ethnography originated in the anthropology, but has been applied to a wide variety of organizations [6]. The methodology described by Spradley [62] for participant observation analysis serves as a starting point to develop an emic or insider's view of the information situation. Although this method is typically applied to field notes, collected through observation, of the language that a group uses, Spradley [62] has described a successful application to a situation with no direct observation.

Taking the selected information operations articles as a form of discourse within the culture, Spradley's ethnosemantic analytic approach was applied to the narratives. As cultural artifacts, these documents "enter the field as a receptacle (of instructions, obligations, contracts, wishes, reports, etc) [and] ... as agents in their own right" [50]. The IO texts were subjected to a domain analysis to discover cultural domains, or categories of "cultural meaning" [62]. Domains consist of cover terms (names), included terms (names of smaller categories), and semantic relationships linking the two categories together. For example, the semantic relationship entitled Strict Inclusion is expressed as " $\mathrm{X}$ is a kind of $\mathrm{Y}$ ", where $\mathrm{X}$ 
is a subcategory and $\mathrm{Y}$ is a domain. An example from the analysis is: "population is a kind of target." Taxonomies were developed next to show relationships among the various elements of individual domains. Analysis of these relationships yielded cultural themes, which then supported the semiotic analysis.

\section{Semiotic Approach}

Semiotics is the study of signs, where a sign "is something which stands to someone for something else in some respect or capacity" [38]. Semiotics "is often encountered in the form of textual analysis" [12] and therefore was appropriate for examining the IO practitioners' narratives, but it can also be applied to anything that conveys meaning, including culture [41] As Barley asserts, semiotics provides an "avenue for conceptualizing and analyzing occupational and organizational cultures" [5], and therefore can be applied to the military organizational culture under consideration.

Semiotic analysis has many forms and methods [12] Liu, 2000; Mick, 1986). Fiol (1989), for example, took a narrative semiotics approach in analyzing whether CEO letters to shareholders reflected underlying organizational boundaries. Liu [38] has applied semiotics to information systems engineering. The information operations research effort described here followed a structuralist approach which proceeds by establishing "the underlying conventions, identifying significant differences and oppositions in an attempt to model the system of categories, relations (syntagmatic and paradigmatic), connotations, distinctions, and rules of combinations employed" [12]. Barley [5] and Mick [41] applied this approach for analyzing artifacts of occupational and organizational cultures and consumer research respectively. One of the strengths of this approach is that it may provide insights "beyond the manifest content of texts" [12].

\section{Rhetorical Criticism}

Rhetorical criticism supplemented the insights from semiotics and the adapted ethnographic analysis approaches by examining how the practitioners and decision makers use words to describe their actions and activities. Rhetoric is "the human use of symbols to communicate" [21], but also "the ways in which signs influence people” [9]. Rhetorical criticism then is "the systematic investigation and explanation of symbolic acts and artifacts for the purpose of understanding rhetorical processes” [21].
Brummett explicitly connects semiotic analysis and rhetorical criticism: "A text is...something that has meaning, a meaning grounded in the culture behind the text, a meaning that can be examined and understood" [9]. Grant [26] combined rhetorical criticism and semiotics to analyze media texts dealing with Ground Zero. Lawson used Blitzer's notion of "rhetorical situation" to examine milblogger (military web loggers) justifications of on-line activities and found evidence of the "information warfare discourse tradition" in their language [36]. Brenner [8] analyzed metaphorical language in Army doctrine relating to information and its uses.

White has expanded the notion of narrative analysis to the analysis of histories, identifying historical text as "a verbal structure in the form of a narrative prose discourse” [70]. He proposed an analysis of realistic prose based on the four rhetorical tropes (Metaphor, Metonymy, Synecdoche, and Irony) which provide "a basis for classifying the deep structural forms" of the text and can be related to particular combinations of "modes of emplotment, argument, and ideological implication" [70]. These modes describe how the author/historian approaches a set of historical data and prefigures it for analysis. As White notes, the various modes and tropes are not combined randomly; there are affinities among them which lead to natural combinations. Combining White's modes with the rhetorical tropes was a means for classifying the narratives of IO practitioners. Identifying consistent rhetorical practices among the authors (the use of a particular trope, for example) provides insights into the underlying cultural factors which affect the integration of IO into the military decision making process.

\section{Synthesis}

The adapted ethnographic, semiotic, and critical methods are distinct in their approaches, but all seek to discover meaning - in a situation, a text, a discourse. A synthesis of results from these different analytic approaches can provide an opportunity for a consilience of the disparate perspectives, bringing them "together into a single, simple, and elegant structure of explanation" [25]. The vehicle for attempting this consilience was the information landscape model [59, 60], with its capacity to consider the interactions of cultural dimensions, technology, and frames of information use. The landscape model, therefore, served as the starting point for the analysis, generating an abductive hypothesis to guide the research and also provided a vehicle for putting the results in context. 


\section{METHODOLOGY APPLICATION}

Articles that described the uses of information operations in a theater of operations were selected from professional military journals and used as source data. An ethnosemantic analysis, based on Spradley's approach [62], identified cultural domains, taxonomies, and themes of information use. Two specific themes were selected for further analysis using semiotics and rhetorical criticism.

The structural semiotic analysis, following the methodology of Manning [39] and Barley [5], found a consistent underlying structure in the articles in the use of language to characterize certain aspects of information operations as equivalent to more traditional combat tasks. The semiotic analysis, therefore, revealed efforts by the military cultures to reduce uncertainty surrounding IO and indicated that Uncertainty Avoidance was playing a role in decisions about information operations.

Rhetorical criticism of the articles focused on another theme from the ethnosemantic analysis: the use of influence operations to stand for all information operations. Influence operations are a human-centric element of $\mathrm{IO}$ focused on influencing the local population, as opposed to such technology-centric elements as Computer Network Operations which are focused on adversary decision makers. Representing the whole of IO by one of its components is an indication of a culture that (1) sees the possibility of overcoming adversity, but in the context of a longterm struggle; (2) views change as an evolving, organic process, and (3) believes current systems and processes are adequate, with only refinement of certain elements required. Influence operations were represented as a microcosm of traditional Army and Marine Corps operations, helping to reduce uncertainty and ambiguity about IO.

The two decision making models described above were the analytic Military Decision Making Process (MDMP) and the commander-centric Recognition Planning Model (RPM). The first relies on doctrine to guide the development and evaluation of competitive courses of action (COA) by the staff. To the degree that IO doctrine was "confusing" or "ambiguous," as characterized by the authors, IO courses of action will not compete well. In addition, the analytic nature of MDMP calls for quantifiable measures of effectiveness (MOE), but even doctrinal documents recognize that MOEs for information operations are difficult to develop. Thus, IO becomes associated with uncertainty and the military organization, already faced with significant uncertainties, tends to fall back on the familiar.

The RPM decision making model, on the other hand, depends on commanders to apply their experience and recognize when IO would be a viable course of action. Until very recently, however, information operations was the purview of specialists or other military services, and bounded by security classifications. Therefore, Army commanders had limited opportunities to develop the necessary experience base. Again, this leads to a tendency to fall back on traditional combat solutions even when those solutions may not provide the best results - at least they are predictable.

It should be noted that as the research project was in its final stages, the U. S. Army published a new operations doctrine, reflective of the experiences in Iraq [64]. The doctrine now recognizes both forms of planning, the analytic and the 'intuitive,' as equally valid and portrays them as ends of a continuous spectrum. The RMP-like form is appropriate when facing familiar circumstances or in a timeconstrained situation. The MDMP is preferred when time permits or when engaged in an operation outside the commander's range of experience.

While each of the dimensions of culture discussed above play a role in decisions about integrating information operations, the research identified Uncertainty Avoidance as the principal factor. To the degree that aspects of IO are seen as unfamiliar or not part of the Army mission, commanders and staff are less likely to treat them on an equal footing with more familiar combat capabilities.

The political frame and the public relations frame identified potential organizational power issues associated with decisions about information operations. While a monarchial mode of information governance might be expected in a military organization, analysis of the articles indicated evidence of two less efficient modes: technological utopianism and feudalism. This helped focus attention on the role of the IO staff officer as a possible "information politician" and led to comparisons with the public relations specialist in industry.

\section{CONCLUSION}

Organizations facing uncertain environments may have to adopt new technologies and perform unfamiliar missions to be successful. The research project which prompted the development of this 
qualitative methodology examined the effects of organizational culture on decision making in this situation. The results from this exploratory methodology will help to provide an entry point for further research to gain a better understanding of the complex information and knowledge ecologies of military decision making. This understanding can in turn lead to better understanding of decision support system requirements and ultimately to a better system implementation.

The methodology described was but one of many possible combination of elements from ethnosemantics, semiotics, and rhetorical criticism. This particular combination, however, produced interesting insights into the cultural factors affecting integration of information operations which were not obvious at the beginning of the investigation. Thus, applying aspects of ethnographic, semiotic, and rhetorical methods has proven a viable approach, and yielded rich data about military organizational culture.

\section{REFERENCES}

1. Atkinson, P. \& Coffey, (2004). Analyzing documentary realities. In D. Silverman (Ed.). Qualitative research: Theory, method, and practice, $2^{\text {nd }}$ ed. (56-75). Thousand Oaks: Sage.

2. Atkinson, P. \& Delamont, S. (2005). Analytic perspectives. In N. K. Denzin \& Y. N. Lincoln (Eds.). The Sage Handbook of Qualitative Research, $3^{\text {rd }}$ ed. (pp. 443 - 466). Thousand Oaks: Sage Publishing.

3. Baker, R. O. (2006). The decisive weapon: A brigade commander's perspective on information operations. Military Review, 86 (3), 13-32.

4. Ball, L. J. \& Ormerod, T. C. (2000). Putting ethnography to work: The case for cognitive ethnography of design. The International Journal of Human-Computer Studies, 53, 147168.

5. Barley, S. R. (1983). Semiotics and the study of occupational and organizational cultures. Administrative Science Quarterly, 28, 393-413.

6. Blythin, S., Rouncefield, M., and Hughes, J. A. (1997). Never mind the ethno' stuff, what does all this mean and what do we do now: Ethnography in the commercial world. Interactions 4(3), 38-47. Retrieved from http://doi.acm.org/10.1145/255392.255400

7. Bolman, L. G. \& Deal, T. E. (2003). Reframing organizations: Artistry, choice, and leadership. San Francisco: Jossey-Bass.

8. Brenner, N.V.M. (2005). Metaphors we kill by: Rhetoric and conceptual structure in U. S. Army doctrine (Doctoral dissertation, University of
Maryland, 2005). Dissertation Abstracts International - A, 66(6), 2198.

9. Brummett, B. (1994). Rhetoric in popular culture. New York: St. Martin's Press.

10. Burcik, V., Kohun, F. G., \& Skovira, R. J. (2007). Analyzing the effect of culture on curricular content: A research conception. Issues in Informing Science and Information Technology, 4, 381-393. Retrieved from http://proceedings.informingscience.org/InSITE2 007/IISIT v4p381-393Burc373.pdf.

11. Campen, A. D. (Ed.). (1992). The first information war: The story of communications, computers and intelligence systems in the Persian Gulf War. Fairfax, Va.: AFCEA International Press.

12. Chandler, D. (2007a). Semiotics: The basics. New York: Routledge.

13. Creswell, J. W. (2003). Research design: Qualitative, quantitative, and mixed method approaches. $2^{\text {nd }}$ ed. Thousand Oaks: Sage Publications.

14. Davenport, T. H., Eccles, R. G., \& Prusak, L. (1992). Information politics. Sloan Management Review, 34(1), 53. Retrieved November 25, 2005, from ABI/INFORM Global.

15. Davenport, T. H. \& Prusak, L. (1998). Working knowledge: How organizations manage what they know. Boston: Harvard Business School Press.

16. Denning, D. E. (1999). Information warfare and security. Reading, MA: Addison-Wesley.

17. Department of Defense. (2006). Quadrennial Defense Report. Retrieved from http://www.defenselink.mil/qdr/p92.

18. Eco, U. (1979). A theory of semiotics. Bloomington: Indiana University Press.

19. Eco, U. (1984). Semiotics and the philosophy of language. Bloomington: Indiana University Press.

20. Fiol, C. MK. (1989). A semiotic analysis of corporate language: Organizational boundaries and joint venturing. Administrative Science Quarterly, 34 (2), 277 - 303.

21. Foss, S. K. (2004). Rhetorical criticism: Exploration and practice. Baltimore: Waverly Press.

22. Geertz, C. (1973). The interpretation of cultures. New York: Basic Books.

23. George, L. \& Skovira, R. J. (2006). Application of an information landscape model to analyze information flows in a community of practice. Issues in Information Systems, 7(2), 129 - 133.

24. Goffman, E. (1974). Frame analysis: An essay on the organization of experience. Cambridge, MA: Harvard University Press. 
25. Gould, S. J. (2003). The hedgehog, the fox, and the magister's pox: Mending the gap between science and the humanities. New York: Harmony Books.

26. Grant, A. J. (2005). Ground zero as holy ground and prelude to holy war. The Journal of American Culture, 28 (1), pp. 49-60.

27. Hamilton, S. N., Miller, W. L., Ott, A., \& Saydjari, O. S. (2001b). The role of game theory in information warfare. Submitted to The CERT Information Survivability Workshop, 2001, Carnegie Mellon University. Retrieved from http://www.cert.org/research /isw/isw2001/papers/Hamilton-31-08-b-1.pdf.

28. Hodder, I. (2003). The interpretation of documents and material culture. In N. K. Denzin \& Y. S. Lincoln (Eds.), Collecting and interpreting qualitative materials (pp. 155-175). Thousand Oaks, CA: Sage.

29. Hofstede, G. \& Hofstede, G. J. (2005). Cultures and organizations: software of the mind. New York: McGraw-Hill.

30. Hughes, J. A., O’Brien, J., Rodden, T., Rouncefield, M., \& Blythin, S. (1997). Designing with ethnography: A presentation framework for design. In S. Coles (Ed.), Proceedings of the Conference on Designing Interactive Systems: Processes, Practices, Methods, and Techniques (Amsterdam, The Netherlands, August 8 - 20, 1997) (pp. 147158). New York: ACM Press. Retrieved from http://doi.acm.org/10.1145/263552.263598.

31. Jabro, A. D. \& Domalski, R. (2005). Stakeholder concerns: A research based campaign to educate community residents about Superfund processes and procedures. $8^{\text {th }}$ International Public Relations Research Conference: The impact of $P R$ in creating a more ethical world: Why can't we all get along? (pp. 175 - 183). South Miami, FL.

32. Joint Chiefs of Staff. (2006). Joint Publication 313. Information operations. Retrieved from http://www.dtic.mil/doctrine/jel/new_pubs/jp3_1 3.pdf.

33. Klein, G. (1999). Sources of power: How people make decisions. Cambridge, MA: MIT Press.

34. Klein, G. \& Calderwood, R. (1996). Investigations of naturalistic decision making and the recognition-primed decision model. (Monograph ARI Research Note 96-43). Alexandria, VA: Army Research Institute for the Behavioral and Social Sciences.

35. Klein, G., Pliske, R., Crandall, B., \& Woods, D. D. (2005). Problem detection. 5Cogn Tech Work, 7, 14-28. Retrieved August 22, 2006 from ABI/INFORM Global.
36. Lawson, S. (2007). Loosing the blogs of war: The advent of "Milblogging" in the post-9/11 U. S. military. Paper presented at Association of Internet Researchers 2007 conference. Available at http://seanlawson.rhetoricaldevices.net/confpapers/Lawson_Loosing \%20the\%20Blogs\%20of\%20War.pdf.

37. Levis, A. H. (2006, January). Normalizing influence operations in the CAOC:

Experimental challenges. Paper presented at Phoenix Challenge 2006, Baltimore, MD.

38. Liu, K. (2000). Semiotics in information systems engineering. Cambridge: Cambridge University Press.

39. Manning, P. K. (1987). Semiotics and fieldwork. Beverly Hills: Sage.

40. Metz, T. F., Garrett, M. W., Hutton, J. E., \& Bush, T. W. (2006). Massing effects in the information domain: A case study in aggressive information operations. Military Review, 86 (3), 2-12.

41. Mick, D. G. (1986). Consumer research and semiotics: Exploring the morphology of signs, symbols, and significance. Journal of Consumer Research 13 (2) 196-213.

42. Norman, D. A. (2002). The design of everyday things. New York: Basic Books.

43. Orlikowski, W. J. \& Baroudi, J. J. (1991). Studying information technology in organizations: Research approaches and assumptions. Information Systems Research, 2 (1), 1-28.

44. Paparone, C. R. \& Reed, G. E. (2008). The reflective military practitioner: How military professionals think in action, 87 (2), 66-76.

45. Paschall, J. F. (2004). Tactical information operations in Operation IRAQI FREEDOM. Marine Corps Gazette, 88(3), 5659. Retrieved November 4, 2007, from Research Library database. (Document ID: 583358831).

46. Paschall, J. F. (2005). IO for Joe: Applying strategic IO at the tactical level. FA Journal, 10 (4), 25-29. Retrieved December 1, 2007, from Research Library database. (Document ID: 913854251).

47. Pather, S. \& Remenyi, D. (2004). Some of the philosophical issues underpinning research in information science: From positivism to critical realism. Proceedings of the 2004 Annual Research Conference of the South African institute of Computer Scientists and Information Technologists on IT research in Developing Countries, 141-146.

48. Peräkylä, A. (2005). Analyzing talk and text. In N. K. Denzin \& Y. N. Lincoln (Eds.). The Sage 
Handbook of Qualitative Research, $3^{\text {rd }}$ ed. (pp. 443 - 466). Thousand Oaks: Sage Publishing.

49. Perry, W. L. \& Moffat, J. (2004). Information sharing among military headquarters: The effects on decisionmaking. Santa Monica, CA: RAND Corporation.

50. Prior, L. (2004). Doing things with documents. In D. Silverman (Ed.). Qualitative research: Theory, method, and practice, $2^{\text {nd }}$ ed. (56-75). Thousand Oaks: Sage.

51. Ridderhof, P. J. (2002). Thinking out of the box: Reading military texts from a different perspective. Naval War College Review, 55 (4), 83-95. Retrieved December 30, 2007, from Research Library database. (Document ID: 272482701).

52. Rosen, S. P. (1991). Winning the next war. Ithaca, NY: Cornell University Press.

53. Ross, K. G., Klein, G. A., Thunholm, P., Schmitt, J. F., \& Baxter, H. C. (2004). The recognition-primed decision model. Military Review, 84 (5), 6-10.

54. Ryle, G. (1971). The thinking of thoughts: What is 'Le Penseur' doing? In Collected papers, vol. 2, 480-496. London: Hutchinson.

55. Sadler, T. (1999). Rhetoric and the death of a top gun: Technology, gender, and the military. Business Communication Quarterly, 62(2), 108111. Retrieved Monday, April 02, 2007 from the Business Source Premier database.

56. Sicoli, P. A. (2005). Filling the information void: Adapting the IO message in post-hostility Iraq. Research monograph, Ft. Leavenworth, KS: School of Advanced Military Studies, U. S. Army Command and General Staff College. Retrieved from http://stinet.dtic.mil/cgibin/GetTRDoc?AD=ADA436260\&Location=U2 \&doc=GetTRDoc.pdf.

57. Simon, H. A. (1997). Administrative behavior. $4^{\text {th }}$ ed. New York: The Free Press.

58. Simon, H. A. (1996). The sciences of the artificial. $3^{\text {rd }}$ ed. Cambridge, MA: MIT Press.

59. Skovira, R.J. (2004). Using information landscape as a model to understand information use and design within organizations. Issues in Information Systems, V (1), 308-314.

60. Skovira, R. J. (2005). Specifying an idea for inquiry about uncertainty avoidance models among Slovak IT professionals in the information society. Proceedings of INFOS 2005, Bratislava, 141-148.

61. Skovira, R. J. (2007). Ontological grounding of a knowledge mapping methodology: Defining data, information, and knowledge. Issues in Information Science, VII (2), 258-264.
62. Spradley, J. P. (1980). Participant observation. New York: Wadsworth Thomson Learning.

63. Trent, S. \& Doty, J. L. (2005). Marketing: An overlooked aspect of information operations. Military Review, 85 (4), 70-74. Retrieved from Research Library database. (Document ID: 902580171).

64. U. S. Army. (2008). FM 3-0. Operations.

65. U. S. Army. (2003). Field Manual 3-13. Information operations: doctrine, tactics, techniques, and procedures. Retrieved from http://www.dtic.mil/doctrine/jel/service_pubs/3_ 13.pdf.

66. U. S. Army. (2001). Field Manual 3-0. Operations. Retrieved from http://www.dtic.mil/doctrine /jel/service_pubs/3_0a.pdf and http://www.dtic.mil/doctrine /jel/service_pubs/3_0b.pdf.

67. U. S. Army. (1997). Field Manual 101-5. Staff organization and operations. Retrieved from http://www.dtic.mil/doctrine/jel/service_pubs/10 1_5.pdf.

68. Wagenhals, L. \& Levis, A. (2000). Course of action development and evaluation. Paper presented at the 2000 Command and Control Research and Technology Symposium, Naval Postgraduate School, Monterey, CA. Retrieved from http://www.dodccrp.org /events/2000_CCRTS/html/pdf_papers/Track_6/ 130.pdf.

69. Wentz, L.K. \& Wagenhals, L. W. (2003). Integration of information operations into effects-based operations: Some observations. Paper presented at the 2003 International Command and Control Research Technology Symposium. Retrieved from www.dodccrp.org/ events/2003/8 ${ }^{\text {th }}$ ICCRTS/pdf/071.pdf. 1-15.

70. White, H. (1975). Metahistory: The historical imagination in nineteenth-century Europe. Baltimore: Johns Hopkins University Press.

71. Woods, D. D., Patterson, E. S., \& Roth, E. M. (2002). Can we ever escape from data overload? A cognitive systems diagnosis. Cognition, Technology \& Work, 4(1), 22-36. Retrieved October 27, 2006, from Research Library database. (Document ID: 701235121).

72. Yu, C. H. (1994, April). Abduction? Deduction? Induction? Is there a logic of exploratory data analysis? Paper presented at the Annual Meeting of American Educational Research Association, New Orleans, Louisiana. ERIC Document Reproduction Service No. ED376173). Retrieved March 1, 2008, from ERIC database. 